\title{
The use software ERGOSHOW in the education of health and safety at work to regardin the safety to children
}

\author{
Sharinna Venturim Zanuncio ${ }^{\mathrm{a}}$, Simone Caldas Tavares Mafra ${ }^{\mathrm{b}}$, Francisco Rebelo $^{\mathrm{c}}$, Ernesto Filgueiras ${ }^{\mathrm{b}}$ \\ ${ }^{a}$ Federal University of Viçosa, Vicosa, Minas Gerais/Brazil-sharinnavz@yahoo.com.br Minas Gerais/Brazil \\ ${ }^{b}$ Home Economics Departament, Higher Education Departament of the Ministry of Education and Culture (SE- \\ Su/MEC), Federal University of Vicosa, Vicosa/State of Minas Gerais/Brazil-sctmafra@ufv.br- \\ ${ }^{c}$ School of Human Kinetics, Technical University of Lisbon-Lisbon/Portugal-frebelo@fmh.utl.pt \\ ${ }^{d}$ School of Human Kinetics, Technical University of Lisbon - Lisbon/Portugal-ernesto@gmail.com
}

\begin{abstract}
It is believed that health and safety of workers should be worked with children and early teenagers, the perspective that adults are more aware of these issues by providing them with health and quality of life in their daily lives, this is want the ERGOSHOW. The choice of media means for transmitting content of Ergonomics, Health and Safety (OSH) is justified because of the great popularity of computer games are among the public of the study, thereby providing a greater assimilation of the content worked. Therefore, the aim of this study was to work with OSH issues related to children between 08 and 12 years old, city of, State of Minas Gerais, Brazil. To achieve this we used the software ERGOSHOW, quizzes, and lecture. One can see that the use of multimedia tools in the learning, especially when considering the reports of mothers according to the different behavior of children after the development of activities, such as parents in correcting posture in relation to computer use.
\end{abstract}

Keywords: Health and safety at work; multimedia; ERGOSHOW; children; educational software

\section{Introduction}

The Protection of Brazilian Yearbook of 2008 shows Brazil as the fifth country in number of accidents in the world, behind only China, India, USA and Indonesia. This publication states that this situation could be exacerbated if all accidents were reported and if all the workers were not considered by the statistics below the existing workforce in the country.

According to the Ministry of Labour, in 2010, between the months of January and July were 50,282 reported accidents (BRAZIL, 2010).

Not only the health and worker safety can be influenced by a lack of knowledge for proper care while performing work activities, such as quality of life can also be influenced, and this is a determining factor for a healthy life, both within the work and in everyday life (individual and family).
The quality of life in this study can be understood as the definition given by Lara-Muñoz and collaborates (1995, cited by Sbardelloto and Pedroso, 2008) that refer to it as a concept of welfare, can be affected by several factors, mainly linked to the physical wellbeing and psychological.

This concept of quality of life is reaffirmed also by Guimarães (1982), which says it involves factors related to health, such as physical well-being, psychological, emotional and mental, but also elements unrelated as family, friends or other life circumstances, and that these factors can affect the quality of life, especially if they are not contributing to meet the expectations and needs of each individual and or social group to which it is related or bound.

Considering the fact mentioned, for safety and health of workers, it is important that it is worked with children and teenagers, helping them to construct these concepts to structured knowledge that can contribute to adults who are more aware of these 
aspects, and provide them with health and quality of life in their daily lives, whether at school or at home.

For this, it is believed that the tool ERGOSHOW was critical in assisting this purpose, since, according to Dias and collaborates (1998), the multimedia system broadens the way people communicate via computer, and these systems have been discussed as motivators of learning, providing so diverse and multifaceted understanding of facts, concepts and procedures.

The choice of media means for transmitting knowledge about of Ergonomics, Safety and Health at Work is justified also by the great popularity that computer games are among young people, awakening in them, more interest in the area and consequently greater assimilation of the knowledge.

In considering the issue presented, this work aimed to study aspects related to the Health and Safety at Work with children between 08 and 12 years old, in State of Minas Gerais, Brazil. More specifically the study was constructed showing the importance of health and safety at work in everyday life of participants, addressing the issues, Labour and Transport of Sitting (Modules I and II of ERGOSHOW, respectively) with those involved in project to subsidize the activities on the theme Health and Safety at Work, developed with the participants different ways of correcting possible situations that lead to accidents at work in their daily lives, the end to detect possible changes in attitudes of children, considering the aspect of Health and Safety, after the interaction of the game with Multimedia ERGOSHOW presented by the tool.

\section{Methodological procedures}

This study was carried out in Vicosa, State of Minas Gerais, Brazil. Its development is due to the presence of the Federal University of Vicosa, which has a population of approximately 12,000 inhabitants, with a combined population of the city, around 71,624 inhabitants, has a population close to 80,000 inhabitants of the municipality.

The city holds its services and community structure, considering the daily life of the University. There are several projects in the area of provision of services designed to meet the demand from alums and employees, teachers and servants of the UFV.

In the city of Vicosa, State of Minas Gerais, Brazil, can observe a high rate of urbanization and social and economic life largely influenced by the student community, especially the university.
The discussion on topics that seek to improve the quality of life of the individual (worker) is fundamentally, especially when you want to have future adults more committed, responsible and concerned about their individual health and work.

The Vicosa is considered "Educating City" because of its largest investments in education, with a significant number of colleges and universities. This fact qualifies this city more than other cities of the region to receive and change knowledge. Given the characteristic presented by the municipality, the test software ERGOSHOW having a positive effect on discussion of the theme proposed for the study namely: formation of attitudes/precepts concerning health, safety at work.

To achieve the objectives, was studied by means of lecture contents regarding the importance of Health and Safety in the daily life of participants, and concepts of ergonomics, a discipline which this contributed to the structuring of the software, used in, this study.

Another instrument used in this study was the ERGOSHOW, software developed at the Laboratory of Ergonomics, Faculty of Human Kinetics (FMH), Technical University of Lisbon, Portugal.

Besides the use of the instruments listed above were administered questionnaires to identify the characteristics of children who participated in the study, and to conduct assessments with parents about possible changes in the attitude of their children, with regard to a greater health concern.

After the knowledge of the data, these were organized considering the issue of dealing, are described and discussed considering the same.

\section{Results and discussion}

The study was developed with three children, with 8 and 11 years old were enrolled in elementary education at private schools in the city of Vicosa, State of Minas Gerais, Brazil. To ensure privacy along with the volunteers in this study were presented using the data to identify children as follows: "Child A", "Child B", "Child C".

To achieve the objectives and facilitate the development of activities, a schedule was prepared for each child, with pre-defined dates and times with parents.

As a first step, was given to the participants talk about issues related to ergonomics, such as: What is ergonomics?; The use of personal protective equipment (PPE); ergonomics as a child, sitting on 
the job - and incorrect posture, transportation loads; way of walking, posture and sleeping on the couch, and condemned actions by physiotherapists. This activity aimed to introduce the issue to be worked by ERGOSHOW.

At the end of the lecture, the children were asked to perform an assessment of the speech, resulting in the following views when asked about what they thought of the lectures:

"I found it interesting, educational and cool" (Child A);

"I found it interesting, I learned things that even I had no idea that existed" (Child C).

Regarding the question of what they had learned and whether they thought this information would be useful to their lives, all children said wich they understand the importance of having a correct posture, not forcing the column to the development of activities in their day by day. Regarding the importance of content addressed to their families, said:

"The correct way to sleep and not to force the column, the development of activities" (Child A);

"The proper way to sit" (Child B);

"All the issues are important to my family" (Child C).

Finally, we presented figures representing postures and correct and incorrect attitudes regarding the development of activities with the objective of verifying the apprehension of the content, getting the hit of $100 \%$ of responses by children.

This information affirm the importance of working the contents of the safety and health at work with the individual as a child, because even if it does not yet have a well structured knowledge on the subject, contact with it allows you to start to familiarize with the same, increasing the interest and mainly present it to the family, so that it can act directly on the quality of life, as stated by Corrêa and Gonçalves (n.d., cited by Gonçalves, 2004), nowadays there is much talk in quality of life, whether personal or professional body and has put all plans to achieve this level of satisfaction.

In this sense it is important to discuss health and safety, as these variables provide the Quality of Life and Quality of Working Life for those involved, and these concepts can be better grasped if delivered by a member of the family because the family is a space conducive to the feedback and construction experiences.
After the lecture, as the second stage of the study, we used the software ERGOSHOW, and the activities provided for therein, taken at three meetings.

To know and identify the contact (using technology) of the participating children with computers to ensure better development activities with the software was applied to them an identity card whose data can be viewed in Table 1 shown below.

Table 1

Identification of contact between children and computers.

\begin{tabular}{|c|c|c|c|}
\hline Issues & $\begin{array}{c}\text { "Child } \\
\text { A" }\end{array}$ & $\begin{array}{c}\text { "Child } \\
\text { B" }\end{array}$ & $\begin{array}{c}\text { "Child } \\
\text { C" }\end{array}$ \\
\hline $\begin{array}{l}\text { Has a computer } \\
\text { at home? }\end{array}$ & Yes & Yes & Yes \\
\hline $\begin{array}{l}\text { Use the } \\
\text { computer to } \\
\text { realize resource } \\
\text { at school? }\end{array}$ & No & No & Yes \\
\hline $\begin{array}{l}\text { How often do } \\
\text { you use your } \\
\text { computer? }\end{array}$ & $\begin{array}{l}\text { Every } \\
\text { day }\end{array}$ & $\begin{array}{c}\text { Three } \\
\text { times a } \\
\text { weak }\end{array}$ & $\begin{array}{c}\text { Three } \\
\text { times a } \\
\text { weak }\end{array}$ \\
\hline $\begin{array}{l}\text { Use the } \\
\text { computer to: }\end{array}$ & $\begin{array}{c}\text { For } \\
\text { other } \\
\text { purposes } \\
\text { (see } \\
\text { videos) }\end{array}$ & $\begin{array}{l}\text { Play and } \\
\text { study }\end{array}$ & $\begin{array}{l}\text { Play, } \\
\text { write } \\
\text { and } \\
\text { study }\end{array}$ \\
\hline $\begin{array}{l}\text { He likes to use } \\
\text { the computer? }\end{array}$ & Very & Little & Very \\
\hline $\begin{array}{l}\text { Who you use } \\
\text { your computer? }\end{array}$ & Alone & $\begin{array}{l}\text { Whith } \\
\text { my } \\
\text { parents }\end{array}$ & Alone \\
\hline $\begin{array}{l}\text { Use the } \\
\text { computer to } \\
\text { realize search in } \\
\text { the Internet? }\end{array}$ & Yes & Yes & Yes \\
\hline $\begin{array}{l}\text { Use the Internet } \\
\text { to: }\end{array}$ & $\begin{array}{c}\text { For } \\
\text { other } \\
\text { purposes } \\
\text { (to play) }\end{array}$ & $\begin{array}{c}\text { Doing } \\
\text { business }\end{array}$ & $\begin{array}{l}\text { Talking } \\
\text { with } \\
\text { friends, } \\
\text { studying } \\
\text { and } \\
\text { doing } \\
\text { business }\end{array}$ \\
\hline
\end{tabular}

Source: Zanuncio and Collaborates, 2009.

These data confirm the growing trend of computer access for children, reinforcing the idea of games media and importance as a tool in the teaching and learning is the same, since the computer must be used in addition to entertainment, and also considered a tool for teaching and learning, as shown in Table 1, two of the three children use the computer to study. This fact reinforced by the study of Vaughan (1994, cited by Primo, 1996) which says that a type of game that is being worked on, due to increased access to computers, video games and the Internet, multimedia is the game, which is defined as any combination of text, graphics, sounds, 
animations and videos in the form of electronic media through the computer or other electronic means.

After application of the questionnaire (second meeting) was working with the students the level I and II Module Weight Transportation ERGOSHOW software, where the issues were addressed, spine and weight transportation. At the end of each level, the software tested the knowledge imparted through the questions to be answered about the content so that participants could move to the next level. In this activity all participants performed well, hitting about $75 \%$ of the questions, which allowed them to proceed to the next level, which demonstrates a good grasp and understanding of thematic concepts worked.

The third meeting was held with children Level III Module Weight Transportation, whose content is about the forces acting on the spine to assume certain positions, as well as the expected position in weight transportation. The module brings you tips on correct postures to avoid damaging the column and eventually experience health problems related to it.

As in Level I, II and III presented the final questions on the subject covered, where children study showed a good performance, demonstrating a good grasp of the content worked. The results obtained allowed the same pass to the next module, which addressed the "Work Sitting."

In the fourth and last meeting, the children developed activities drew attention to Module II software ERGOSHOW, who was sitting Labour. This in turn was divided into three levels, addressing issues about work, especially in computer terminal. This place is as important, because the children spend a considerable time in this activity. As can be seen when they were asked how many times a week using the computer, and the response was, three times a week and every day.

At the end of Module II levels, as well as in Module I, questions were presented to assess the apprehension of the knowledge received during the meetings. Children performed better than in Module I, probably due to the theme to be more associated with the day by day, because theirs adopt this posture along the day in front of a computer terminal or in the video game.

From greater interaction with the children who participated in the case study it was revealed that the seizure of knowledge took place in a more dynamic and interesting considered from the point of view of these, depending on the methodology used for presentation of information, since this required interaction and participation during the explanations.
So that they could build knowledge, and this may meet the individual abilities. This fact reinforces the trend of using software in the process of teaching and learning of children, as says Primo (1996), the multimedia game combines learning, and educational titles that bring the same appeal these existing adventure. This complicity between the title educational multimedia and game highlights that most CD-ROMs aimed at education brings, that is, games that aim to assess and assimilate the contents and determine the lessons learned in a playful manner, ie through play.

At the end of activities, with the aim of assessing what was developed was applied to children an interview, obtaining the following responses.

When asked: what they thought about this project. The responders said:

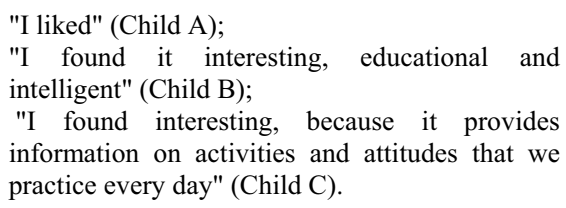

When asked about whether they thought that what they learned during the activities and games were for their lives, all said yes. The Child $\mathrm{C}$ said, "had no knowledge of many subjects spoken during the meetings, but I learned from the activities performed".

In relation to what they found most important;

"I thought important to know that we must
respect our hearts" (Child A);
"What I liked most was knowing I need to have a
different position with my body to do something"
(Child B);
"I liked the part that talks about Work Sitting"
(Child C).

At the end when asked what they thought of the experience of learning through play, they mentioned the following questions:

\footnotetext{
"I felt good" (Child A);

"I liked" (Child B);

"I found it interesting because I never imagined that this option had to learn" (Child C).
}

Primo (1996) says, the media technologies have a great capacity to present content in an intuitive and enjoyable, noting that children and teenagers spend much of their time with video games, which can generate the remoteness of the study and the literature, so it is believed that multimedia presents a potential combination of these two worlds. The CD- 
ROM educational and reference, through interactive technology and multimedia can present content through different media involved in a similar environment to that of video games, both in aesthetics and in interactivity.

As the end of the study, after the development of activities with the children, was applied to the same parents a questionnaire to evaluate the validity of the knowledge and the behavior change in the everyday life of family, noting that only the mothers responded to the same, in a way that reinforces the idea that maintenance is the responsibility of women with assistance and child care, reinforcing the idea that there is no sexual division of domestic work, even though the families are experiencing change in their profile family. When asked if they noticed any change in your child's behavior with respect to the subject worked, after the start of activities and what were the perceived changes were obtained the following information:

\begin{abstract}
"Yes, my son began to pay more attention to how it should sleep, and lower when it was loading heavy lifting, carrying his school bag ... I think he was more attentive to some aspects were presented in the textbooks "(The mother of the Child A);

"Yes, my son is watching me and corrected me the other day on my way to answer the phone, he told me the position I was, was not correct and tell me how I had to stay even when I was on the screen the computer and also what would be the correct position to sit down "(mother of the Child B);

"I did not observe difference, but you may have been yes, but that's because I'm away from it all day, oh it's hard to notice the differences quickly. But he comments on what they have learned, only that he needed to practice what is learned "(mother of the Child C).
\end{abstract}

When asked if their children have made comments on the development of activities, and what are these, they replied:

"He did not comment much about the meetings
do not, but I believe the knowledge he has
received are being charged for it" (The mother of
the Child A);
"He told me he watched a movie and also played
in ERGOSHOW" (mother of the Child B);
"Said the first meeting was cool and when the
subject was reading the booklets that were
distributed much he commented that he was
right, then he said, his way to sleep, to carry the
backpack, he was doing all right as it should do
"(Mother of Child C).

Another inquiry was made as to what they thought the textbooks were distributed and made available to them during the course of activities: the mother of "Child A" said that these were very interesting, but saw his son staring at them, but did not know if this was the same claim, but the content of textbooks, she found it very useful, pointing out even though you need to put into practice the subjects, the mother of "Child B" said the textbooks are great and that after the read, he watched his posture when working at the computer and is trying to correct it, since it already has experienced back pain when it gets all day with the same attitude, the mother of "Child C "said that he found interesting, well prepared, with content useful to their day by day.

Finally, when asked whether they believed that the subject worked, namely, educating children on issues of health and safety at work is important, and why, we obtained the following responses: the mother of "Child A" said yes, it allows the child to reflect on their attitudes in day by day, and with that change your behavior, and also believes that if it worked the change in behavior early in the perspective of choosing the right way, this child an adult may be more aware of what is needed to not crash, and an adult who will not have as much difficulty in following rules when these are to keep you safe and healthy, the mother of "Child B" but said, because it is good to know in order to prevent, especially in regard to sports for children, and when they learn that even children can avoid future problems, already the mother of "Child C" also said he believes the work is an important issue, nothing also who believes that the chances of having consenting adults regarding their attitudes and behavior in relation to their health and safety will be much higher if the knowledge on the subject in question began to be passed on in infancy.

Given this context, one can see that the use of multimedia tools in the learning of health and safety issue in working with children arises of fundamental importance, especially when considering the reports of mothers regarding the behavior exhibited by children after the development of activities, reinforcing their importance as an instrument of interaction/information between society and family, with the transmission of knowledge is acquired in schools, social groups or projects (which would explain these projects). Specifically regarding the content worked, namely, health and safety at work, it is clear that if the child is considered as the instrument of interaction/information between society and family, these can be provided to obtain a better quality of life with consequent improvement of 
health conditions, and the use of the tool ERGOSHOW as a methodology facilitated the seizure of the contents because the software is working and provide dynamic interaction between child and computer, whereas the medium used to display the content (computer) is encouraging for the child so she feels motivated to learn.

\section{Concluding remarks}

As previously mentioned, Brazil is a country where more accidents are recorded in the world. But this situation could be exacerbated if all accidents were reported and if all the workers were not considered by the statistics below the existing workforce in the country. With regard to safety and health of workers, it is important that this be worked with children and early teenagers, helping them to construct these concepts so that the constructed knowledge can contribute to adults who are more involved and aware of these aspects as well as provide them with health and quality of life in their daily lives, whether at school or at home.

Considering the characteristic of the public referred to the choice of multimedia means for transmitting content of Ergonomics, Safety and Health at Work was considered appropriate and justified, as can be seen, depending on the popularity that computer games are among the youngest, these arousing more interest in the area and consequently greater assimilation of content worked, and it was possible the perception of the interaction between software and children, made possible by computer use. It was felt that the introductory lectures provided the reduction in inefficiency in the transfer of content. In this sense it is considered important lectures and interviews addition, the application of ERGOSHOW to broaden participants' knowledge and assessment of learning achieved.

To do so, given the scope of this work was to verify the importance of the multimedia content stream to be sought of Ergonomics, Safety and Health at Work, considering children aged 8 to 12 years old, and the Health and Safety at Work can be understood as the set of technical, administrative, educational, medical and psychological that are employed to prevent accidents by eliminating unsafe conditions or the environment, whether instructing or persuading people in the implementation of preventive practices, as the accident prevention is the act of putting into practice the rules and safety measures in order to avoid the occurrence of accidents, as the ergonomics is to establish parameters for the adjustment of working conditions to the psychophysiological characteristics of workers in order to provide maximum comfort, safety and efficient performance, it was realized that in fact the learning of these concepts was facilitated and better perceived by participants due to the system and methodology used. Where the children to interact with the ERGOSHOW, and the concepts that take their lives by also transmitting the content to their families, especially to have a correct posture while performing a job.

Again, when considering the multimedia system, we emphasize its importance, since this, the game introduce learning with the appeal of adventure games, colors, sounds, animations, videos, texts and the possibility of interaction, they hold user to the instrument, therefore facilitating learning, since it becomes "a fun game." This complicity between the title and multimedia educational game that highlights the most CD-ROMs aimed at bringing education, that is, games that aim to assess and assimilate the contents and determine the lessons learned through play.

Given this context, we could see that multimedia tools such as ERGOSHOW, can contribute to the formation of adults more aware and concerned about their Health and Safety at Work, from the work among children and interactive multimedia system. Being that despite not being a longitudinal study, it was considered that children are strong vehicles for interaction/information between the society, represented here by the study, and his family, for taking the concepts learned to their daily lives, believing that not only children are more conscious adults, but also that their families will be better prepared to control risk situations at work or occupational diseases, because they are better manipulated by incorporating concepts related to Ergonomics, Health and Safety at Work for your day by day, whether at home, at work or school.

Finally it is suggested that the matter is not closed, because a country is perceived longevity progressive, where the children of today are the adults and the elderly themselves tomorrow in an economically active population, ie, future workers is extremely important that these are equip to deal with possible situations of risk, which can be realized with the software ERGOSHOW experiencing. 


\section{References}

[1] BRAZILIAN Yearbook Protection 2008 - special edition magazine protection. 14 Ed. 2008. Available at: $<$ http://www.protecao.com.br/novo/template/page.asp?cod $=95$ $8 \&$ CodMenu=958\&Lbt=0>. Accessed: September 19, 2010.

[2] BRAZIL. Ministry of Labor and Employment. 2010. Available at: <http://www.mte.gov.br>. Accessed: September 15, 2010

[3] Dias, Paulo; GOMES, Maria João; and CÔRREA, Ana Paula Sousa. Hypermedia and Education. Braga: Teacher's Home Edition. 1998.

[4] Guimarães, Roberto Pereira. Quality of Urban Life. 2. ed. Rio de Janeiro, $1982 . \quad$ Available at: $<$ http://www.unicamp.br/fea/ortega/temas530/vanessam.htm>. Accessed: June 26, 2010.

[5] Gonçalves, Aguinaldo. Public health, physical activity and quality of life. In: Understanding and Discussing Health and Physical Activity. Rio de Janeiro: Ed. Guanabara Koogan, 2004.

[6] Pedrosa, Rosemeri Smith; and SBARDELLOTO, Gabriela. Quality of life and social support in patients with chronic renal failure: theoretical review. Virtual Journal of Health Psychology and Health, 4 years, n.7. Belo Horizonte, 2008. Available at: <http://susanaalamy.sites.uol.com.br/psicopio n7 32.pdf $>$. Accessed: August 25, 2010.

[7] Primo, Alex Fernando Teixeira. Multimedia and education. Magazine devoted to cultural, Blumenau, SC, 18 years, n.60, p.83-88, Sept.-Dec. 1996. Available at: $<$ http://usr.psico.ufrgs.br/ aprimo/pb/educa.htm>. Accessed: April 1, 2010. 